\title{
Affect of growth regulators and irrigation on potato yield in unstable moistening regions
}

\author{
Sergey V. Zhevora \\ Lorch Potato Research Institute, Moscow region, Russian Federation \\ zhevora@yandex.ru
}

\begin{abstract}
The article presents the results of studies (2014-2016) concerning the assessment of the use of growth regulators (Energia-M, Vigor Forte, Atonik Plus) in combination with irrigation in the field experiment during potato cultivation (Udacha variety). The study was conducted in the Ilek district of the Orenburg region, Krasnokholmskaya Agro-firm. The soil was residual meadow southern chernozem. According to the effectiveness of impact on potato yield in southern chernozem of the Orenburg region, the factors were as follows: irrigation provided yield increase from $40 \%$ (without fertilizers) to $65 \ldots 66 \%$ (NPK + Regulators); mineral fertilizers provided yield increase from $41 \%$ (without irrigation) to $59 \%$ (with irrigation); growth regulators on optimal variants provided yield increase: Vigor Forte / Atonik (tubers + plants) $-12 \ldots 13 \%$ for bogharic agriculture; $16 \ldots 19 \%$ with irrigation to the corresponding mineral ground. The maximum yield of potatoes under irrigation was obtained on variants with 2-fold application of Atonic and Vigor Forte growth regulators (tubers + plants) - 44.2 ..44.5 t/ha, an increase to the mineral fertilizing $\left(\mathrm{N}_{100} \mathrm{P}_{120} \mathrm{~K}_{100}\right)-17.9 \ldots 18.6 \%$. The optimum soil moisture was $70 \ldots 75 \% \mathrm{FC}$ in the irrigated area. This increased the payback of $1 \mathrm{~kg}$ NPK due to an increase in yield from $19.6 \mathrm{~kg}$ (mineral fertilizing, bogharic agriculture) to $55.6 \ldots 67.2 \mathrm{~kg}$ of tubers (combination of NPK, irrigation and regulators). Water consumption decreased from $212 \mathrm{~m}^{3} / \mathrm{t}$ (mineral fertilizing) to $140 \ldots 145 \mathrm{~m}^{3} / \mathrm{t}$ (combination of mineral fertilizers and plant growth regulators).
\end{abstract}

Key words: potato, irrigation, growth regulators

\section{Article history:}

Received: 4 March 2019. Accepted: 28 October 2019.

\section{For citation:}

Zhevora SV. Affect of growth regulators and irrigation on potato yield in unstable moistening regions. RUDN Journal of Agronomy and Animal Industries. 2019; 14(4):362-373. doi: 10.22363/2312797X-2019-14-4-362-373

Севора С.В., 2019.

(c) (i) This work is licensed under a Creative Commons Attribution 4.0 International License https://creativecommons.org/licenses/by/4.0/ 
Научная статья

\title{
Применение регуляторов роста и орошения на картофеле в регионах с неустойчивым увлажнением
}

\author{
C.В. Жевора \\ ФБГНУ Всероссийский научно-исследовательский институт \\ картофельного хозяйства им. А.Г. Лорха, \\ Московская область, Российская Федеращия \\ zhevora@yandex.ru
}

\begin{abstract}
Аннотация. Приведены результаты исследований 2014 - 2016 гг. по выращиванию картофеля (сорт Удача) с применением регуляторов роста (Энергия-М, Вигор Форте, Атоник Плюс) в сочетании с орошением в полевом опыте, который проводился в Илекском районе Оренбургской области (ООО «Агрофирма Краснохолмская») на черноземе южном, остаточно-луговатом. По эффективности действия на урожайность картофеля в условиях чернозема южного Оренбургской области изучаемые факторы расположились следующим образом: орошение - прибавки от 40\% (без удобрений) до $65 \ldots 66 \%$ (NPK + Регуляторы); минеральные удобрения — от 41\% (без орошения) до 59\% (с орошением); регуляторы роста на оптимальных вариантах: Вигор Форте / Атоник (клубни + растения) $-12 \ldots 13 \%$ на богаре; $16 \ldots 19 \%$ при орошении относительно соответствующих минеральных фонов. Максимальная урожайность картофеля в условиях орошения получена на вариантах с 2-кратным применением регуляторов роста Атоник и Вигор Форте (клубни + растения) $44,2 \ldots 44,5 \mathrm{~T} /$ га, прибавка к минеральному фону $\left(\mathrm{N}_{100} \mathrm{P}_{120} \mathrm{~K}_{100}\right)-17,9 \ldots 18,6 \%$. Оптимальная влажность почвы 70...75\% от НB на орошаемом участке увеличивала окупаемость 1 кг д. в. NPK прибавкой урожая с 19,6 кг (минеральный фон, богара) до 55,6...67,2 кг клубней (сочетание NPK, поливов и регуляторов). Расход воды на образование прибавки урожая снижался с $212 \mathrm{~m}^{3} /$ т (минеральный фон) до $140 \ldots 145 \mathrm{~m}^{3} / \mathrm{T}$ на вариантах сочетания минеральных удобрений с применением регуляторов роста растений.
\end{abstract}

Ключевые слова: картофель, орошение, регуляторы роста

\section{История статьи:}

Поступила в редакцию 4 марта 2019 г. Принята к публикации 28 октября 2019 г.

\section{Для цитирования:}

Жевора C.B. Применение регуляторов роста и орошения на картофеле в регионах с неустойчивым увлажнением // Вестник Российского университета дружбы народов. Серия: Агрономия и животноводство. 2019. Т. 14. № 4. С. 362-373. doi: 10.22363/2312-797Х-2019-14-4-362-373

\section{Introduction}

Potential soil fertility, hydrothermal conditions, and biological features of the cultivated crop are the leading factors determining productivity of agrocenosis $[1-4]$.

Potato cultivation on an industrial scale in regions with a deficit of rainfall is beneficial only under irrigation conditions, since potatoes produce a stable crop with sufficient moisture $[2,5,6]$. The damage from drought is enormous: 1972 and 2010 served as a vivid example, in the first case, shortage of potato production in the USSR amounted to 9 million tons, and in 20109 million tons were not received only in Russia [3]. 
Irrigation requires increased plant fertilizing, since with a sufficient amount of nutrients in the soil, the effect of irrigation is enhanced and water consumption for formation of a production unit is reduced $[5,6]$.

In potato practice, growth regulators are of scientific and practical interest as tools for hormonal effects on physiological processes of plants, especially in order to increase reproduction rate and yield of the seed fraction of valuable varieties and high reproductions of seed potatoes [7].

Application of growth regulators combined with irrigation should be considered as indispensable elements of potato cultivation technology in the Central region of Russia [3, 6].

The goal of the research was to increase potato yields and yield of tuber seed fraction, depending on irrigation and synthetic phytohormone analogues.

\section{Materials and methods}

The field experiment on growing potatoes using growth regulators (Energia-M, Vigor Forte, Atonik Plus) in combination with irrigation was conducted in 2014-2016 in the Ilek district of the Orenburg region (Krasnokholmskaya Agrofirm). The experimental scheme is given in Table 1.

The following growth regulators were used in the experiment: Energia-M, (crystalline powder, a.i. - $855 \mathrm{~g} / \mathrm{kg}$ of orthocresoxyacetic acid triethanolammonium salt + $95 \mathrm{~g} / \mathrm{kg}$ of 1-chloromethylsilatran): pre-treatment of tubers $-4 \mathrm{~g} / \mathrm{t} / 101$ of water; foliar treatment - $20 \mathrm{~g} \mathrm{ha} / 3001$ of water; Vigor Forte, (crystalline powder, a.i. - $100 \mathrm{~g} / \mathrm{kg}$ of orthocresoxy acetic acid triethanolammonium salt + macro- $(\mathrm{N}, \mathrm{P}, \mathrm{K}, \mathrm{Mg})$ and microelements (Fe, Mn, Zn, Cu, B, Mo)): pre-treatment of tubers - $15 \mathrm{~g} / \mathrm{t} / 101$ of water; foliar treatment - $50 \mathrm{~g} / \mathrm{ha} / 3001$ of water; Atonik Plus, (water soluble concentrate, a.i. $9 \mathrm{~g} / \mathrm{l}$ sodium para-nitrophenolate $(\mathrm{p}-\mathrm{NP})+6 \mathrm{~g} / \mathrm{l}$ sodium ortho-nitrophenolate $(\mathrm{o}-\mathrm{NP})+$ $3 \mathrm{~g} / \mathrm{l}$ sodium 5-nitrogwaycolate $(5-\mathrm{NG})$ : concentration for treating tubers and foliar treatments - $30 \mathrm{ml} / \mathrm{t} / 101$ of water and $900 \mathrm{ml} / \mathrm{ha} / 300 \mathrm{l}$ of water, respectively.

Potato variety - Udacha (early). Planting pattern - $75 \times 30 \mathrm{~cm}$, plant density 44,000 plants/ha. The total area of the plot is $60 \mathrm{~m}^{2}$, accounting $-40.5 \mathrm{~m}^{2}$. The experiment had three replications. Location of plots was randomized within the re replications. Pre-planting treatment of tubers with growth regulators was carried out 2 days before planting with a Kwazar hand sprayer at the rate of 101 of operating solution per 1 ton of seed tubers. Foliar spraying of plants with growth regulators was carried out with a Kwazar sprayer in the morning or evening during budding — beginning of flowering of potatoes. The irrigation and non-irrigation unit of the experiment was located nearby on the same field. To maintain moisture content of the active soil layer in the irrigated area not lower than $75 \ldots 80 \% \mathrm{FC}, 6$ to 9 irrigations were carried out with DM-100 Fregat sprinkler machine with $2700 \ldots 3600 \mathrm{~m}^{3} /$ ha irrigation rate. Different amounts of irrigation were carried out over the years: in 2014: 3 irrigations in June, 3 in July, 3 in August; in 2015 and 2016: 2 irrigations in June, 3 in July, 1 in August, irrigation rate was $400 \ldots 460 \mathrm{~m}^{3} / \mathrm{ha}$.

The predecessor plant was Bromus inermis. Fertilizing was full dose $\left(\mathrm{N}_{100} \mathrm{P}_{120} \mathrm{~K}_{100}\right)$. Planting date was I decade of May, and harvesting was at the end of August. 
The soil of the experimental plot - southern chernozem, residual meadow, weakly humus, medium thick, medium loamy with a humus content of $3.2 \%$ in the arable layer, it was characterized by a low level of nitrogen mobile forms $(6.35 \mathrm{mg} / 100 \mathrm{~g}$ of soil $)$ and phosphorus (8.63 ...9.96 mg/100 g of soil), and medium level of exchangeable potassium $(22 \mathrm{mg} / 100 \mathrm{~g}$ of soil).

The accounts and observations in the experiments were carried out in full accordance with GOST (Russian State Standard) and standard methods. The significance of differences between the means was calculated by the method of two-way analysis of variance at a 5\% significance level (Dospekhov B.A., 1985) and AgCStat program add-ons for Excel (authors Gonchar-Zaikin P.P., Chertov V.G., 2012).

\section{Results and discussion}

The experimental data obtained confirmed the importance of irrigation as an effective factor in increasing and stabilizing potato yields (Table 1). Potato productivity without irrigation was in the range from $23.9 \mathrm{t} / \mathrm{ha}$ (mineral fertilizing) to $26.8 \ldots 27.1 \mathrm{t} / \mathrm{ha}$ in variants with growth regulator treatment.

Table 1

Average potato yields in 2014-2016

\begin{tabular}{|c|c|c|c|c|c|c|}
\hline \multirow{3}{*}{ Варианты } & \multicolumn{3}{|c|}{ Rainfed } & \multicolumn{3}{|c|}{ Irrigated } \\
\hline & \multirow{2}{*}{$\begin{array}{c}\text { Yield, } \\
\text { t/ha }\end{array}$} & \multicolumn{2}{|c|}{ Increase } & \multirow{2}{*}{ Yield, t/ha } & \multicolumn{2}{|c|}{ Increase } \\
\hline & & t/ha & $\%$ & & t/ha & $\%$ \\
\hline 1. No fertilization & 16.9 & - & - & 23.6 & - & - \\
\hline 2. $\mathrm{N}_{100} \mathrm{P}_{120} \mathrm{~K}_{100}$ & 23.9 & - & - & 37.5 & - & - \\
\hline 3. $\begin{aligned} \mathrm{N}_{100} \mathrm{P}_{120} \mathrm{~K}_{100} \\
\text { + Energia tubers }\end{aligned}$ & 25.7 & 1.8 & 7.5 & 41.0 & 3.5 & 9.3 \\
\hline 4. $\begin{aligned} \mathrm{N}_{100} \mathrm{P}_{120} \mathrm{~K}_{100} \\
\text { + Energia tubers } \\
\text { + plants }\end{aligned}$ & 26.3 & 2.4 & 10.0 & 43.7 & 6.2 & 16.5 \\
\hline 5. $\begin{aligned} & \mathrm{N}_{100} \mathrm{P}_{120} \mathrm{~K}_{100} \\
& + \text { Vigor Forte tubers }\end{aligned}$ & 26.6 & 2.7 & 11.3 & 42.2 & 4.7 & 12.5 \\
\hline 6. $\begin{aligned} & \mathrm{N}_{100} \mathrm{P}_{120} \mathrm{~K}_{100} \\
&+ \text { Vigor Forte tubers } \\
&+ \text { plants } \\
&\end{aligned}$ & 27.1 & 3.2 & 13.4 & 44.5 & 7.0 & 18.6 \\
\hline 7. $\begin{aligned} & \mathrm{N}_{100} \mathrm{P}_{120} \mathrm{~K}_{100} \\
& + \text { Atonic tubers }\end{aligned}$ & 26.2 & 2.3 & 9.6 & 42.3 & 4.8 & 12.8 \\
\hline 8. $\begin{aligned} & \mathrm{N}_{100} \mathrm{P}_{120} \mathrm{~K}_{100} \\
& + \text { Atonic tubers } \\
& + \text { plants }\end{aligned}$ & 26.8 & 2.9 & 12.1 & 44.2 & 6.7 & 17.9 \\
\hline
\end{tabular}

$\mathrm{LSD}_{05} 1.5$; precision $1.7 \%$; irrigation $65.5 \%$; fertilization $27.4 \%$

Over the years of research, in the block of experiment variants on dry land, efficiency of mineral fertilizers amounted to $41.4 \%$, growth regulator Energia $\mathrm{M}$ $7.5 \ldots 10.0 \%$, Vigor Forte - 11.3...13.4\%, Atonik Plus - 9.6..12.1\%. The maximum potato yield was obtained in variants with double use of growth regulators (tubers + plants) - 26.8...27.1 t/ha.

On average, over the research years, potato yields from irrigation increased 1.6...1.7 fold and amounted to $37.5 \ldots 44.5 \mathrm{t} / \mathrm{ha}$. 
In the block of experiment variants with irrigation, efficiency of mineral fertilizers increased to $58.9 \%$, Energia $M$ regulator - 9.3...16.5\%, Vigor Forte - 12.5...18.6\%, Atonik Plus - 12.8..17, 9\%, i.e. when optimizing soil moisture, the effectiveness of mineral fertilizers and growth regulators increased.

The highest potato yield under irrigation conditions was obtained in variants with 2-fold application of Atonik and Vigor Forte growth regulators (tubers + plants) $44.2 \ldots 44.5 \mathrm{t} / \mathrm{ha}$, increase in mineral background - $17.9 \ldots 18.6 \%$.

Depending on climatic conditions of the year, the level of yield and increase varied. Yield increases from the effect of mineral fertilizers on the dry land were as follows: $34.0 \%(2014) \rightarrow 38.4 \%$ (2015) $\rightarrow$ 52.1\% (2016); under irrigation: $62.3 \%$ (2014) $\rightarrow$ $63.8 \%(2015) \rightarrow 50.8 \%$ (2016). The largest increase from mineral fertilizers was noted in 2014 and 2015, which indicated a high irrigation efficiency in dry years.

According to the increase in potato productivity in the conditions of southern chernozem of the Orenburg region, the studied factors were located as follows:

— irrigation - increases from 40\% (without fertilizers), 57\% (mineral fertilizers) and up to $65 . .66 \%$ (NPK + PGR);

- mineral fertilizers - 41\% (without irrigation) and 59\% (under irrigation);

- growth regulators: Vigor Forte / Atonik (tubers + plants) - 12...13\% on dry land; $16 . . .19 \%$ under irrigation and mineral fertilizing.

Combination of the optimal humidity regime and growth regulators under NPK fertilizing contributed to an increase in the number of tubers in terms of 1 bush and 1 hectare (Fig. 1).

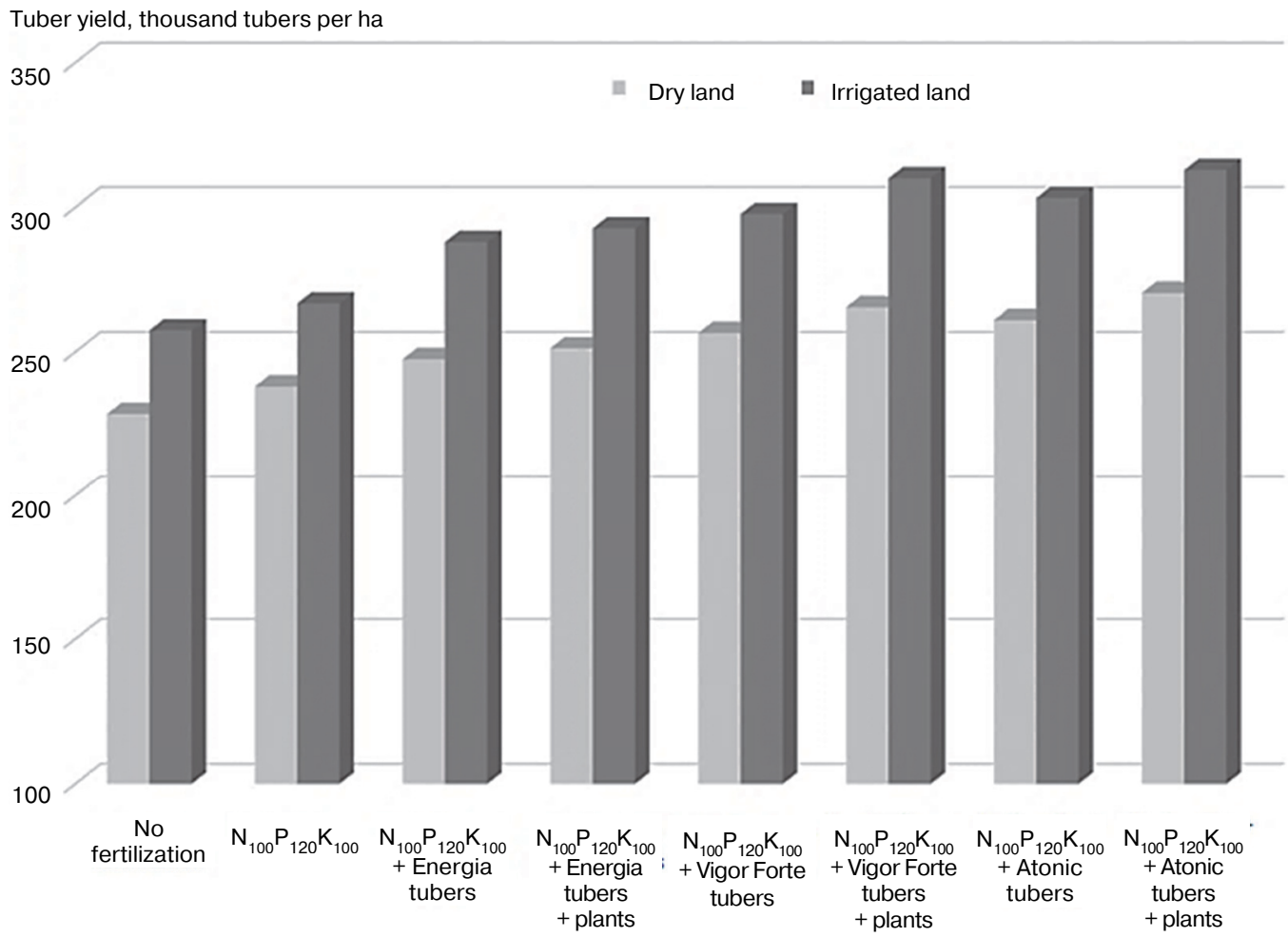

Fig. 1. Yield of seed fraction depending on growth regulators, processing methods and irrigation (average for 2014-2016) 
On average, over the research years, the greatest yield of seed fraction was observed in the irrigation plot variants with 2-fold use of the following regulators: Vigor Forte (tubers + plants) -310 thousand tubers/ha, Atonik (tubers + plants) - 313 thousand tubers/ha, which was 16.1 and 17.2\% higher than NPK fertilizing (variant without growth regulators) -267 thousand tubers/ha.

An analysis of the data on starch yield from 1 ha in conditions of the Southern Urals showed that when irrigation and growth regulators were used with application of mineral fertilizers during potato cultivation, high starch yield was achieved up to $52.8 \ldots 59.0 \mathrm{c} /$ ha, despite its lower concentration in tubers.

The decrease in starch content in tubers in variants under irrigation (by $0.2 \ldots .0 .6 \%$ ) was due to a more substantial increase in yield and marketability, i.e. due to an increase in the dimensional characteristics of tubers, however, size and quality of the commercial fraction of potatoes were in a balanced ratio, which led to a significant increase in starch per unit area.

Stable and optimal soil moisture $70 \ldots 75 \%$ FC in the irrigated area increased the payback of $1 \mathrm{~kg}$ a.i. NPK by yield increase from $19.6 \mathrm{~kg}$ (mineral fertilizing, dry land) to $55.6 \ldots 67.2 \mathrm{~kg}$ of tubers (combination of NPK, irrigation and PGR).

Water consumption for formation of yield increase decreased from $212 \mathrm{~m}^{3} / \mathrm{t}$ (mineral fertilizing) to $140 \ldots 145 \mathrm{~m}^{3} / \mathrm{t}$ in the variants for combining mineral fertilizers and plant growth regulators (Table 2 ).

Table 2

NPK payback by yield increase (average for 2014-2016)

\begin{tabular}{|l|c|c|c|c|c|c|c|}
\hline \multicolumn{1}{|c|}{ Indicators } & $\begin{array}{c}\mathrm{N}_{100} \mathrm{P}_{120} \mathrm{~K}_{100} \\
\text { (NPK) }\end{array}$ & $\begin{array}{c}\text { NPK } \\
+ \text { Energia } \\
\text { tubers }\end{array}$ & $\begin{array}{c}\text { NPK } \\
\text { + Energia } \\
\text { tubers } \\
\text { plants }\end{array}$ & $\begin{array}{c}\text { NPK } \\
\text { +Vigor Forte } \\
\text { tubers }\end{array}$ & $\begin{array}{c}\text { NPK } \\
\text { +Vigor Forte } \\
\text { tubers } \\
+ \text { plants }\end{array}$ & $\begin{array}{c}\text { NPK } \\
+ \text { Atonic } \\
\text { tubers }\end{array}$ & $\begin{array}{c}\text { NPK } \\
+ \text { Atonic } \\
\text { tubers } \\
+ \text { plants }\end{array}$ \\
\hline \multicolumn{7}{|c|}{ Dry land } \\
\hline Increase, $\mathrm{t} / \mathrm{ha}$ & 6.3 & 8.0 & 9.0 & 8.4 & 8.9 & 8.2 & 9.0 \\
\hline Payback, $\mathrm{kg} / \mathrm{kg}$ & 19.6 & 25.0 & 28.1 & 26.3 & 27.8 & 25.6 & 28.1 \\
\hline \multicolumn{7}{|c|}{ Irrigation } \\
\hline Increase, $\mathrm{t} / \mathrm{ha}$ & 14.2 & 17.8 & 21.4 & 18.6 & 20.8 & 18.5 & 21.5 \\
\hline Payback, $\mathrm{kg} / \mathrm{kg}$ & 44.4 & 55.6 & 66.9 & 58.1 & 65.0 & 57.8 & 67.2 \\
\hline $\begin{array}{l}\text { Water consumption } \\
\text { for increase, } \mathrm{m}^{3} / \mathrm{t}\end{array}$ & 212 & 169 & 141 & 162 & 145 & 163 & 140 \\
\hline
\end{tabular}

\section{Conclusions}

Experimental data convincingly show that in unstable moistening regions of Russia, it is necessary to switch to growing potatoes under irrigation. The economic benefits of using all chemicals are doubled and even tripled if the applied agrochemicals get into evenly moistened soil and plants that are not stressed by moisture deficiency.

Achieving high yields — at the level $41.0 \ldots 44.5 \mathrm{t} /$ ha and marketability of $88 . . .90 \%$ in the irrigated area resulted from:

1) planting early plastic potato variety (Udacha);

2) use of balanced dose of mineral fertilizers and complex growth regulators for tuber treatment and foliar spraying. 
The calculation of economic efficiency according to the research results showed that the use of biologically active agents for seed treatment and combination of this agricultural method with foliar spraying with growth regulators both on irrigation and on dry land were economically effective.

The use of growth regulators Vigor Forte (tubers + foliar treatment) and Atonik (tubers + foliar treatment) under $\mathrm{N}_{100} \mathrm{P}_{120} \mathrm{~K}_{100}$ fertilizers in combination with irrigation was significantly more effective than using only fertilizers on a dry land: value of the conditional income increased 4 -fold, cost recovery - by $6 \%$, and production cost decreased by $30 \%$.

The use of irrigation and plant growth regulators under balanced mineral fertilization are indispensable elements of potato cultivation technology, resulting in high yields, increased number of tubers of seed fraction and increased starch content per unit area.

\section{Введение}

Потенциальное плодородие почвы, гидротермические условия и биологические особенности возделываемой культуры являются ведущими факторами, определяющими продуктивность агроценоза [1-4].

Возделывание картофеля в промышленных масштабах в регионах с дефицитом осадков является выгодным только в условиях орошения, поскольку картофель дает стабильный урожай при условии достаточного увлажнения $[2,5,6]$. Ущерб от засухи колоссальный: ярким примером послужили 1972 и 2010 гг., в первом случае недобор объема производства картофеля по СССР составил 9 млн т, а в 2010 г. 9 млн т недобраны только по России [3].

В связи с проведением орошения возрастают требования к технологии возделывания, особенно к питанию растений, так как при достаточном количестве питательных веществ в почве усиливается действие орошения и уменьшается расход воды на образование единицы продукции $[5,6]$.

В практике картофелеводства научно-практический интерес представляют регуляторы роста как инструменты гормонального воздействия на физиологические процессы растения, особенно в целях повышения коэффициента размножения и выхода семенной фракции ценных сортов и высоких репродукций семенного картофеля [7].

Применение регуляторов роста в сочетании с орошением должны рассматриваться как незаменимые элементы технологии возделывания картофеля в Центральном регионе России [3, 6].

Цель исследований: повышение урожайности картофеля и выхода семенной фракции клубней в зависимости от применения поливов и синтетических аналогов фитогормонов.

\section{Материалы и методы}

В 2014-2016 гг. в Илекском районе Оренбургской области (ООО «Агрофирма Краснохолмская») проводился полевой опыт по выращиванию картофеля с применением регуляторов роста (Энергия-М, Вигор Форте, Атоник Плюс) в сочетании с орошением. Схема опыта приведена в табл. 1. 
В опыте применяли следующие регуляторы роста: Энергия- $M$, КРП, д.в. 855 г/кг ортокрезоксиуксусной кислоты триэтаноламмониевая соль +95 г/кг 1-хлорметилсилатран: предпосадочная обработка клубней - 4 г/ т/10 л воды; некорневая обработка - 20 г/га/300 л воды; Вигор Форте, КРП, д.в. - 100 г/кг ортокрезоксиуксусной кислоты триэтаноламмониевая соль + макро- (N, P, K, Mg) и микроэлементы (Fe, $\mathrm{Mn}, \mathrm{Zn}, \mathrm{Cu}, \mathrm{B}, \mathrm{Mo})$ : предпосадочная обработка клубней 15 г/т/10 л воды; некорневая обработка - 50 г/га/300 л воды; Атоник Плюс, ВРК, д.в. - 9 г/л натрия пара-нитрофенолята (p-NP) + 6 г/л натрия орто-нитрофенолята (o-NP) + 3 г/л натрия 5-нитрогваяколята (5-NG): концентрация для обработки клубней и некорневых обработок — 30 мл/т/10 л воды и 900 мл/га/300 л воды.

Сорт картофеля - Удача (ранний). Схема посадки - $75 \times 30$ см, густота стояния растений 44000 шт. /га. Общая площадь делянки 60 м², учетная - 40,5 м². Повторность трехкратная. Расположение делянок рендомизированное внутри повторений. Предпосадочную обработку клубней регуляторами роста проводили за 2 дня до посадки ручным опрыскивателем Kwazar из расчета 10 л рабочего раствора на 1 т семенных клубней. Некорневое опрыскивание растений регуляторами роста проводили опрыскивателем Kwazar в утреннее или вечернее время суток в период бутонизации - начало цветения картофеля. Поливной и не поливной блок опыта располагались рядом на одном поле. Для поддержания влажности активного слоя почвы на орошаемом участке не ниже $75 . .80 \%$ НВ за годы исследований проводили от 6 до 9 поливов дождевальной машиной ДМ - 100 «Фрегат» с оросительной нормой $2700 \ldots 3600 \mathrm{~m}^{3} /$ га. По годам было проведено различное количество поливов: в 2014 г. 3 полива - в июне, 3 - в июле, 3 - в августе; в 2015 и 2016 гг. - 2 полива в июне, 3 - в июле, 1 - в августе, поливная норма - 400..460 м³ га.

Предшественник - кострец безостый. Фоном питания служила полная доза минеральных удобрений $\left(\mathrm{N}_{100} \mathrm{P}_{120} \mathrm{~K}_{100}\right)$. Срок посадки - I декада мая. Уборка конец августа.

Почва опытного участка — чернозем южный, остаточно-луговатый, слабогумусированный, среднемощный, среднесуглинистый с содержанием гумуса в пахотном слое $3,2 \%$, характеризовался низкой обеспеченностью подвижными формами азота (6,35 мг/100 г почвы) и фосфора $(8,63 \ldots 9,96$ мг/100 г почвы) и средней (22 мг/100 г почвы) - обменным калием.

Учеты и наблюдения в опытах осуществляли в полном соответствии с ГОСТами и стандартными методами. Достоверность различий между средними вычисляли методом двухфакторного дисперсионного анализа при 5\% уровне значимости (Доспехов Б.А., 1985) и программы AgCStat - надстройки к Excel (авторы Гончар-Зайкин П.П., Чертов В.Г., 2012).

\section{Результаты и обсуждение}

Экспериментальные данные, полученные в опыте, подтвердили значение орошения как мощного фактора повышения и стабилизации урожайности картофеля (табл. 1). Урожайность картофеля на участке без проведения поливов находилась в интервале от 23,9 т/га (минеральный фон) до 26,8...27,1 т/га на вариантах с регуляторами роста. 
Урожайность картофеля в среднем за 2014-2016 гг.

\begin{tabular}{|c|c|c|c|c|c|c|}
\hline \multirow{3}{*}{ Варианты } & \multicolumn{3}{|c|}{ На богаре } & \multicolumn{3}{|c|}{ На поливах } \\
\hline & \multirow{2}{*}{$\begin{array}{c}\text { Урожай- } \\
\text { ность, т/га }\end{array}$} & \multicolumn{2}{|c|}{ Прибавки } & \multirow{2}{*}{$\begin{array}{c}\text { Урожай- } \\
\text { ность, т/га }\end{array}$} & \multicolumn{2}{|c|}{ Прибавки } \\
\hline & & т/га & $\%$ & & т/га & $\%$ \\
\hline 1. Без удобрений & 16,9 & - & - & 23,6 & - & - \\
\hline 2. Фон $\mathrm{N}_{100} \mathrm{P}_{120} \mathrm{~K}_{100}$ & 23,9 & - & - & 37,5 & - & - \\
\hline $\begin{array}{l}\text { 3. Фон + Энергия } \\
\text { клубни }\end{array}$ & 25,7 & 1,8 & 7,5 & 41,0 & 3,5 & 9,3 \\
\hline $\begin{array}{l}\text { 4. } \text { Фон + Энергия } \\
\text { клубни + растения }\end{array}$ & 26,3 & 2,4 & 10,0 & 43,7 & 6,2 & 16,5 \\
\hline $\begin{array}{l}\text { 5. Фон + Вигор Форте } \\
\text { клубни }\end{array}$ & 26,6 & 2,7 & 11,3 & 42,2 & 4,7 & 12,5 \\
\hline $\begin{array}{l}\text { 6. Фон + Вигор Форте } \\
\text { клубни + растения }\end{array}$ & 27,1 & 3,2 & 13,4 & 44,5 & 7,0 & 18,6 \\
\hline 7. Фон + Атоник клубни & 26,2 & 2,3 & 9,6 & 42,3 & 4,8 & 12,8 \\
\hline $\begin{array}{l}\text { 8. Фон + Атоник клубни } \\
+ \text { растения }\end{array}$ & 26,8 & 2,9 & 12,1 & 44,2 & 6,7 & 17,9 \\
\hline
\end{tabular}

$\mathrm{HCP}_{05} 1,5 ;$ точность 1,7\%; влияние поливов $65,5 \%$; удобрений $27,4 \%$.

В блоке вариантов опыта на богаре за годы исследований эффективность минеральных удобрений составила $41,4 \%$, регулятора роста Энергия М 7,5...10,0\%, Вигор Форте - 11,3...13,4\%, Атоник Плюс — 9,6..12,1\%. Максимальная урожайность картофеля получена в вариантах с двукратным применением регуляторов роста (клубни + растения) - 26,8...27,1 т/га.

В среднем за годы исследований урожайность картофеля от орошения увеличивалась в $1,6 \ldots 1,7$ раза и составляла $37,5 \ldots 44,5$ т/га.

В блоке вариантов опыта с поливами эффективность минеральных удобрений повышалась до 58,9\%, регулятора Энергия $\mathrm{M}$ - 9,3...16,5\%, Вигор Форте $12,5 \ldots 18,6 \%$, Атоник Плюс - 12,8 ..17,9\%, т.е. при оптимизации влажности почвы эффективность минеральных удобрений и регуляторов роста возрастала.

Максимальная урожайность картофеля в условиях орошения получена на вариантах с 2-кратным применением регуляторов роста Атоник и Вигор Форте (клубни + растения) - 44,2..44,5 т/га, прибавка к минеральному фону $17,9 \ldots 18,6 \%$.

В зависимости от условий года уровень урожайности и прибавки варьировали. Прибавки урожайности от действия минеральных удобрений на богаре расположились следующим образом: 34,0\% (2014 г.) $\rightarrow$ 38,4\% (2015 г.) $\rightarrow$ 52,1\% (2016 г.); на орошении $62,3 \%$ (2014 г.) $\rightarrow 63,8 \%$ (2015 г.) $\rightarrow 50,8 \%$ (2016 г.), т.е. наибольшее увеличение прибавок от минеральных удобрений отмечалось в 2014 и 2015 гг., что свидетельствует о высокой эффективности орошения в засушливые годы.

По величине прибавок урожайности картофеля в условиях чернозема южного Оренбургской области изучаемые факторы расположились следующим образом:

— орошение - прибавки от 40\% (без удобрений), 57\% на минеральном фоне и до $65 \ldots 66 \%$ (NPK + PPP);

— минеральные удобрения - 41\% (без орошения) и 59\% (с орошением);

— регуляторы роста на оптимальных вариантах: Вигор Форте / Атоник (клубни + растения $)-12 \ldots 13 \%$ на богаре; $16 \ldots 19 \%$ при орошении относительно минерального фона. 


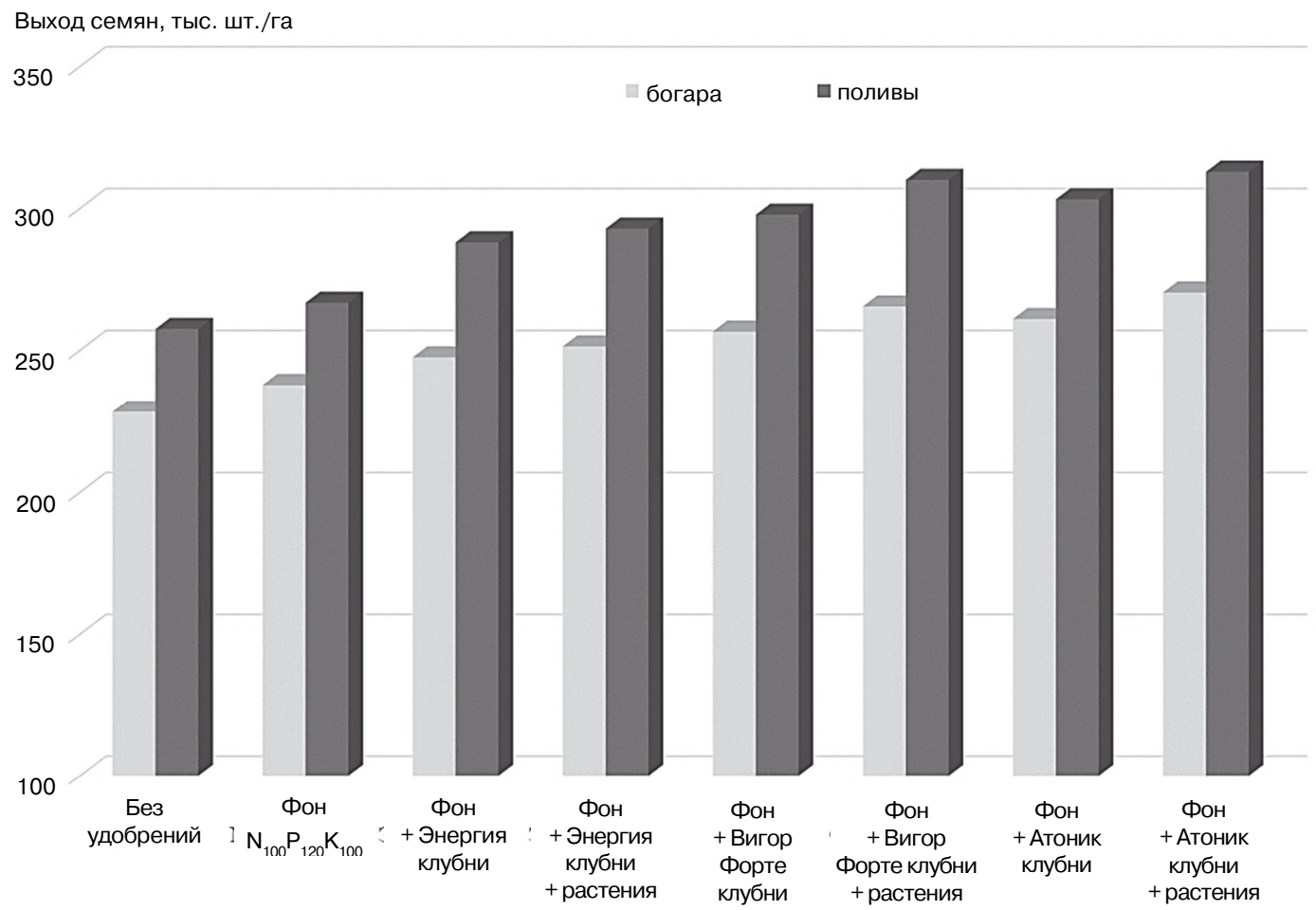

Рис. 1. Выход семенной фракции в зависимости от применения регуляторов роста, способов обработки и поливов (среднее 2014-2016 гг.)

Сочетание оптимального режима влажности и регуляторов роста на фоне NPK способствовало увеличению количества клубней в пересчете на 1 куст и на 1 гектар посадок (рис. 1).

В среднем за годы исследований наибольший выход семенной фракции наблюдался на вариантах поливного участка при 2-кратном применении следующих регуляторов: Вигор Форте (клубни + растения) - 310 тыс. шт./га, Атоник (клубни + растения) - 313 тыс. шт./га, что на 16,1 и 17,2\% выше фона NPK (вариант без регуляторов роста) - 267 тыс. шт./га.

Анализ полученных данных по выходу крахмала с 1 га в условиях Южного Урала показал, что при использовании поливов и регуляторов роста на фоне сбалансированных доз минеральных удобрений при выращивании картофеля достигается высокий сбор крахмала — до 52,8 ..59,0 ц/га, несмотря на более низкую его концентрацию в клубнях.

Снижение содержания крахмала в клубнях по вариантам опыта на поливном участке (на $0,2 \ldots 0,6 \%$ ) происходило за счет более существенного роста урожайности и его товарности, т.е. за счет роста размерных характеристик клубней, однако, величина товарной фракции картофеля и качество продукции находились в сбалансированном соотношении, что привело к существенному росту сбора крахмала с единицы площади.

Стабильная и оптимальная влажность почвы 70...75\% от НВ на орошаемом участке увеличивала окупаемость 1 кг д.в. NPK прибавкой урожая с 19,6 кг (минеральный фон, богара) до 55,6...67,2 кг клубней (сочетание NPK, поливов и PPP). 
Окупаемость NPK прибавкой урожая, среднее за 2014-2016 гг.

\begin{tabular}{|c|c|c|c|c|c|c|c|}
\hline Показатели & $\begin{array}{c}\text { Фон } \\
\mathrm{N}_{100} \mathrm{P}_{120} \mathrm{~K}_{100}\end{array}$ & $\begin{array}{c}\text { Фон } \\
+ \text { Энергия } \\
\text { клубни }\end{array}$ & $\begin{array}{c}\text { Фон } \\
+ \text { Энергия } \\
\text { клубни } \\
+ \text { растения }\end{array}$ & $\begin{array}{c}\text { Фон } \\
+ \text { Вигор } \\
\text { Форте } \\
\text { клубни }\end{array}$ & $\begin{array}{c}\text { Фон } \\
+ \text { Вигор } \\
\text { Форте } \\
\text { клубни } \\
+ \text { растения }\end{array}$ & $\begin{array}{c}\text { Фон } \\
+ \text { Атоник } \\
\text { клубни }\end{array}$ & $\begin{array}{c}\text { Фон } \\
+ \text { Атоник } \\
\text { клубни } \\
+ \text { растения }\end{array}$ \\
\hline \multicolumn{8}{|c|}{ Богара } \\
\hline Прибавка, т/га & 6,3 & 8,0 & 9,0 & 8,4 & 8,9 & 8,2 & 9,0 \\
\hline Окупаемость, кг/кг & 19,6 & 25,0 & 28,1 & 26,3 & 27,8 & 25,6 & 28,1 \\
\hline \multicolumn{8}{|c|}{ Поливной участок } \\
\hline Прибавка, т/га & 14,2 & 17,8 & 21,4 & 18,6 & 20,8 & 18,5 & 21,5 \\
\hline Окупаемость, кг/кг & 44,4 & 55,6 & 66.9 & 58,1 & 65,0 & 57,8 & 67,2 \\
\hline $\begin{array}{l}\text { Расход воды } \\
\text { на прибавку, м³/т }\end{array}$ & 212 & 169 & 141 & 162 & 145 & 163 & 140 \\
\hline
\end{tabular}

Расход воды на образование прибавки урожая снижался с 212 м³/т (минеральный фон) до $140 \ldots 145 \mathrm{~m}^{3} /$ т на вариантах сочетания минеральных удобрений с применением регуляторов роста растений (табл. 2).

\section{Заключение}

Экспериментальные данные убедительно показывают, что в регионах России с неустойчивым влагообеспечением необходимо переходить на выращивание картофеля с применением поливов. Экономическая выгода от применения всех средств химизации удваивается и даже утраивается, если применяемые агрохимикаты попадают в равномерно увлажненную почву и на растения, которые не испытывают стресс от дефицита влаги.

Достижению высоких урожаев — 41,0..44,5 т/га и товарности $88 \ldots 90 \%$ на поливном участке способствовали:

1) посадка раннего пластичного сорта картофеля (с. Удача);

2) использование сбалансированной по элементам питания дозы минеральных удобрений и регуляторов роста комплексного действия для обработки клубней и некорневого опрыскивания ботвы.

Расчет экономической эффективности по результатам исследований показал, что применение биологически активных препаратов для обработки семенного материала и сочетание этого агроприема с некорневым опрыскиванием регуляторами роста как на орошении, так и на богаре было экономически оправдано.

Применение регуляторов роста Вигор Форте (клубни + некорневая обработка растений) и Атоник (клубни + некорневая обработка растений) на фоне полной дозы минеральных удобрений $\mathrm{N}_{100} \mathrm{P}_{120} \mathrm{~K}_{100}$ в сочетании с поливами было существенно выгоднее, чем применение одних минеральных удобрений на богаре: величина условного дохода повышалась в 4 раза, окупаемость затрат - на 6\%, и снижалась себестоимость продукции - на $30 \%$.

Применение орошения и регуляторов роста растений на фоне сбалансированных доз минеральных удобрений - незаменимые элементы технологии возделывания картофеля, позволяющие получать высокую урожайность, увеличивать количество клубней семенной фракции и сбор крахмала с единицы площади. 


\title{
References
}

1. Akhmedov AD. Reliability of elements of drop irrigation systems depending on quality of irrigation water. In: Rol' melioratsii vodnogo khozyaistva v innovatsionnom razvitii APK : materialy mezhdunarodnoi nauchno-prakticheskoi konferentsii. Ch. I. Melioratsiya i rekul'tivatsiya zemel' [A role of melioration of water management in innovative development of AIC: proceedings of the international scientific and practical conference. Part I. Melioration and recultivation of lands. Moscow: MGUP Publ.; 2012. p. 11.

2. Kolesnikov LD. Pomni o zasukhe [Remember a drought]. Chelyabinsk: Yuzhno-Ural'skoe knizhnoe izdatel'stvo Publ.; 1970.

3. Korshunov AV, Rakhimov RL. Irrigation and fertilizing are guarantors of high potato yield. Potato and vegetables. 2011; (6): 7-10.

4. Shabanov AE, Kiselev AI, Fedotova LS. Parameters of potential yield of potato varieties from the Breeding Center of the All-Russian Research Institute of Potato Breeding. Zemledelie. 2018; (5):34-36. doi: 10.24411/0044-3913-2018-10509

5. Dubenok NI, Mushinskij AA, Vasilev AA, Gerasimova EV. Technology of potato cultivation in steppe and forest-steppe zones of the southern Urals under conditions of irrigation. Achievements of Science and Technology of AIC. 2016; 30 (7):71-74.

6. Cheremisin AI. Irrigation of potatoes - effective method of increase in productivity. In: Sibirskie uchenye - agrarno-promyshlennomu kompleksu [The Siberian scientists - to an agrarian and industrial complex]. Omsk; 2000. p. 28-30.

7. Rakitin YV. Khimicheskie regulyatory zhiznedeyatel'nosti rastenii: Izbrannye trudy [Chemical regulators of activity of plants: Chosen works]. Moscow: Nauka Publ.; 1983.

\section{Библиографический список}

1. Ахмедов А.Д. Надежность элементов систем капельного орошения в зависимости от качества поливной воды // Роль мелиорации водного хозяйства в инновационном развитии АПК: материалы международной научно-практической конференции. Ч. І. Мелиорация и рекультивация земель. М.: МГУП, 2012. С. 11.

2. Колесников Л.Д. Помни о засухе. Челябинск: Южно-Уральское книжное изд-во, 1970. 130 с.

3. Коршунов А.В., Рахимов Р.Л. Орошение и удобрение - гаранты высоких урожаев картофеля // Картофель и овощи. 2011. № 6. С. 7-10.

4. Шабанов А.Э., Киселев А.И., Федотова Л.С. Параметры потенциальной урожайности сортов картофеля селекционного центра ВНИИКХ // Земледелие. 2018. № 5. С. 34-36. DOI: $10.24411 / 0044-3913-2018-10509$

5. Дубенок Н.И., Мушинский А.А., Васильев А.А., Герасимова Е.В. Технологии возделывания картофеля в степной и лесостепной зонах Южного Урала в условиях орошения // Достижения науки и техники АПК. 2016. Т. 30. № 7. С. 71-74.

6. Черемисин. А.И. Орошение картофеля - эффективный прием повышения урожайности // Сибирские ученые - аграрно-промышленному комплексу. Омск, 2000. С. 28-30.

7. Ракитин Ю.В. Химические регуляторы жизнедеятельности растений: Избранные труды. М.: Наука, 1983. 264 с.

\author{
About the author: \\ Zhevora Sergey Valentinovich - Candidate of Agricultural Sciences, Director, Lorch Potato Research \\ Institute, 23/B, ul. Lorha, Kraskovo village, Lyubertsy district, Moscow region, 140051, Russian \\ Federation; e-mail: zhevora@yandex.ru
}

\section{Об авторе:}

Жевора Сергей Валентинович - кандидат сельскохозяйственных наук, директор, ФГБНУ Всероссийский научно-исследовательский институт картофельного хозяйства имени А.Г. Лорха, Российская Федерацция, 140051, Московская область, Люберецкий район, поселок Красково, ул. Лорха, д. 23, литер В; e-mail: zhevora@yandex.ru 